\title{
Investing in futures
}

\author{
Hannah Dalgleish
}

Any predictions about the composition of London's economy, or the kind of city it will be to live or work in, in 2062 would rely on wild estimates and presumptions. Looking back 50 years to the 1960s, when Wilson's Labour administration was in power and still presiding over a largely state controlled economy, who would have known we would be where we are now? A time when there were not too many global companies operating in London and the Welfare State and public sector as a whole was as strong as ever. Jobs were created and valued, and services delivered, for the collective good with minimal questions regarding efficiency or cost benefit analysis.

We are now in a period of continuing privatisation and scaling back of the public sector. A time when the state only intervenes when there is deemed to be a failure in the market. A time when the rise of the individual has led to much greater personal freedoms, which has further liberalised society at large, especially in London. The liberalisation of the economy has resulted in a surging increase in wealth and prosperity of a small minority of London residents whilst the rest have seen marginal improvements in real time earnings. More worrying is the widening of the gap between those at the top and those at the bottom, and the negative knock on effects that this rising income inequality brings. All of this is exacerbated in London, due to the concentration of financial services which has added value to commercial and residential rents and associated services. In the face of continued austerity, and prioritisation of the financial services, one can only dream that the London of 2062 could be so very different...

The London I would like to see in 2062 would, on the surface, look very much as it does now. However, if you looked a bit closer at the economic make-up of the city, and spent some time in its communities, you would soon begin to notice the differences.

After 45 years of investment in green technology, and state intervention and investment in other sectors, such as digital and extensive support of social enterprises and small businesses, the London economy has diversified and is far more robust. Investment in sustainable sectors has created a lot of jobs and training opportunities, especially for young people, and has increased innovation to the point that the UK (with London playing its part) is finally catching up with, and challenging, its continental partners in terms of commitment to greening the economy. 2062. Pp. 123-125. London: Ubiquity Press. DOI: http://dx.doi.org/10.5334/bag.q 
The city is thriving, still seen to many as the economic powerhouse of the world, but it has lost its special privileges and influence. Governments are no longer bound to prioritise the interests of financial services. The Tobin Tax, brought in by the EU, has generated substantial income for all governments to reinvest back into public services and the increased corporation tax and income taxes of $80 \%$ of those earning more than $£ 1$ million a year hasn't driven a swathe of banks or private sector firms out of London. Nor has there been the widely expected departure to tax havens of those on higher incomes. It is now the widely held belief that markets can be a good servant but are always a bad master. This change in consciousness has brought about much tighter regulations of the banking sector and a slow move towards democratisation of private sector firms. Moreover, the rejection of GDP as the best way of calculating prosperity has also allowed for a faster move towards polices that capture and value social and sustainable outcomes. In a nutshell, growth is not the driving force behind decision-making in London anymore.

The state is around the same size as it was 40 years ago, but is now much more of an enabler with citizens taking a much more active role in delivering services. In London there has been a phenomenal rise in activism with communities running their local amenities, using their open space and taking ownership of key buildings and infrastructure. The outsourcing of services to Social Enterprises and the Voluntary and Community Sector has further helped to localise provision, and has also ensured vital services which derive no profit are still being delivered. The method of delivery has been transformed, with the collaboration and process valued as equally as the end result.

One of the most innovative progressions in London has been the move towards sharing the workload between a greater number of people. This has helped stimulate job creation and now more people than ever are able to work four-day weeks, enabling more time to be spent with friends, family and on general leisure. This transition has further helped the move towards more active citizenship with many people taking on voluntary roles within their own community.

The introduction of the living wage and a much fairer tax system has created an incentive to work. Jobs that once represented little in the way of value, self-worth or satisfaction are starting to become more appealing as people's attitudes in society are slowly changing, and gaps in pay aren't quite as staggering.

All of these national shifts are much more apparent in London which had the furthest to travel from a base of huge polarisation and income inequality. London is now a city that feels more cohesive, local communities are making decisions and the state is acting in those communities interest. House building is much more focussed on creating medium density family housing, aligned to the needs of growing population.

How did we get here? Or perhaps I should rephrase and ask how can we get here?

There is a growing collective consciousness around fairness. Over the last decade there has been a growing understanding of the need to take climate change more seriously, and to challenge the growth agenda. The election of Françoise Hollande to the French Presidency in 2012 suggests that moving towards a social democratic model isn't beyond possibility. All over London new creative bottom-up approaches are being developed and delivered, many of which can be viewed as pilots of best practice. The challenge is to channel the investment into these social projects and away from top-down public/private ventures, which see little benefit for end users and surrounding neighbourhoods.

London 2062 could be magnificent, a place where everyone is able to live, flourish and realise his or her potential. A lot of work needs to be done and we need to continue to challenge the status quo. In times of austerity creativity thrives, as does alternative thinking. We have a right to dream and the ability to make these dreams reality. 


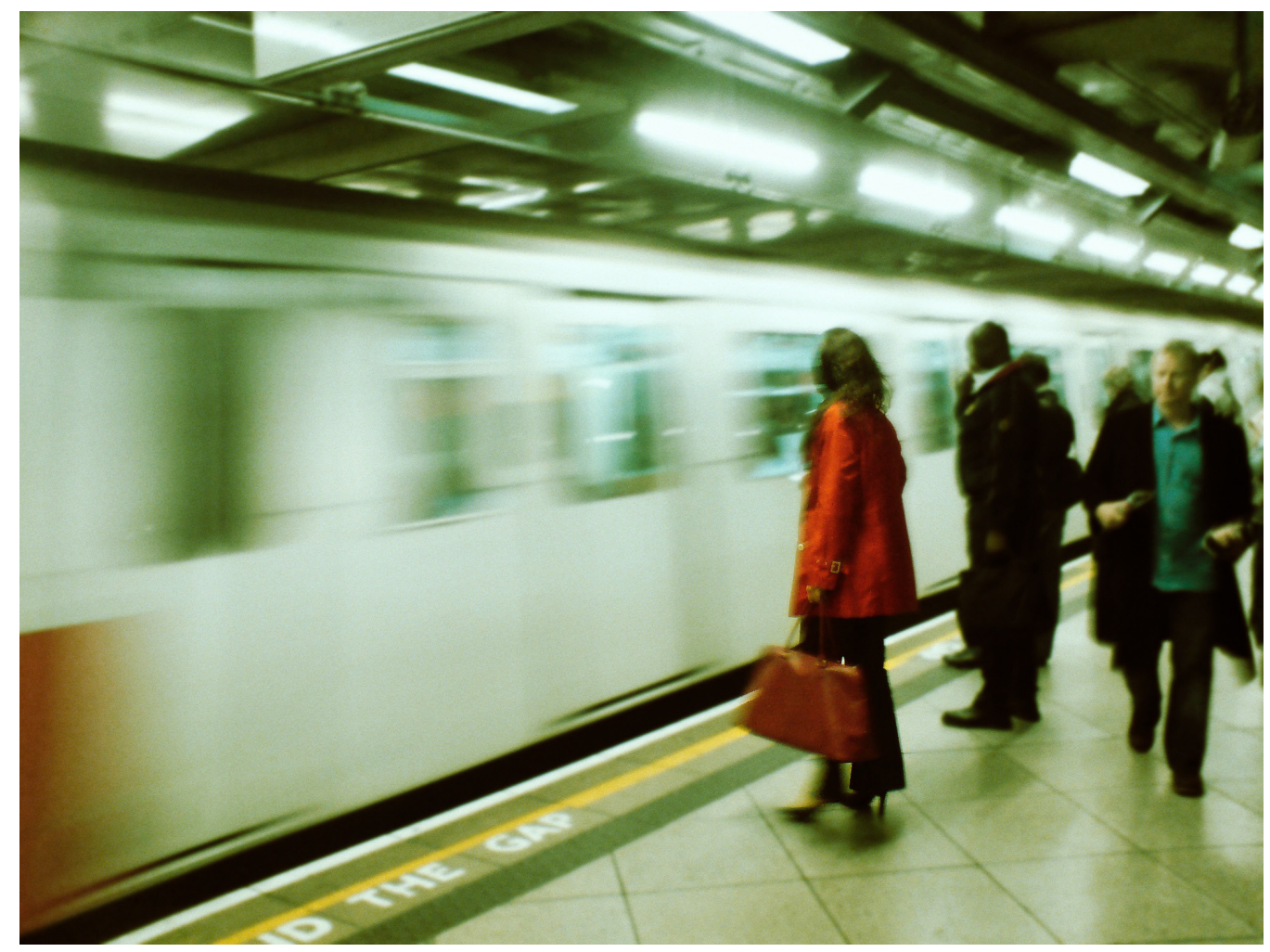

